\title{
High Rate Water Treatment Plant System: Successful Implementation
}

\author{
Mohajit \\ Research Fellow of Alexander von Humboldt Foundation Germany - 2002 \\ Institute of Technology Bandung - Indonesia \\ Email:mohajito@hotmail.com
}

\begin{abstract}
The High Rate Water Treatment Plant (HR-WTP) system, which is inexpensive, effective and efficient, has been developed to reduce the common operational problems, and also as an alternative for the development of water treatment plant systems capacity in Indonesia. HR-WTP-system is superior to those of conventional WTP-systems in respect to its capacity, performance, as well as operational liability of the system.

Mathematical model of the HR-WTP system had been developed and simulation using the mathematical model as well as field observation had been clarified.

Implementation of HR-WTP-system in up-rating of the Dekeng-WTP system at PDAM Kota Bogor proved successful in increasing the plant capacity from its original of 500 Lps to more than 1200 Lps. Another successful application of HR-WTP-system was experienced in the upgrading and up-rating of the Pedindang-WTP system at PDAM Kota Pangkalpinang where the plant capacity can be increased from its original of 50 Lps to 300 Lps. The performance of the WTP-system was also significantly improved from poor performance to very good performance.
\end{abstract}

Keywords: conventional system, filtration rate, high rate system, surface loading

\section{Introduction}

The demand of municipal drinking water in Indonesia is always increasing in direct proportion to population growth and to increasing industrial water demands. However, instead of increased capacities and services, the municipal water supplies are constrained by limited financial factors. The water treatment plant systems in Indonesia have a total capacity of around 100.000 Lps which serve more or less 100.000 .000 population equivalent. Only less than $30 \%$ of the population is covered by these water treatment plant systems.

Furthermore, there are operational problems of the water treatment plant (WTP) system in some cities in Indonesia (even though they are operated at low to medium loading rate) especially in the sedimentation units, e.g., sludge carry over, flow distribution, temperature effect, density flow, algal growth, scale deposits, wind effect, etc. (Mohajit, 2002). Due to these problems, the filter unit of the water treatment plant systems become inefficient because of its frequent clogging of the filter media. In a normal operation without such a problem the filter unit of the water treatment plant system may work with a backwashing cycles of around 24-48 hours. The more frequent the filter is backwashed the more inefficient the filter unit would be.

If operational problems of the water treatment plant system can be solved and the loading rate of the system can also be increased then the systems will become more efficient and effective therefore 
the capacity of the water service may be increased and thus the demand of municipal drinking water might be supplied (Mohajit, 2010).

The objective of this work is to find any methods to increase the production and service capacity of the municipal water treatment plant system in order to reach the millennium development goals in water supply sector in Indonesia, where an additional capacity of ca 150,000 Lps should be developed within a 15 years period.

\section{Material and Methods}

The HR-WTP system had been implemented successfully at Dekeng WTP system at PDAM Kota Bogor and Pedindang WTP system at PDAM Kota Pangkalpinang. The WTP systems were investigated and modified by introducing a new configuration of the systems to increase its capacity (up to double or even three fold) as well as to improve its performance.

Mathematical model of the WTP system had been developed and simulation using the mathematical model as well as field observation had been clarified. The detailed report of the successful application of HR-WTP system for Dekeng and Pedindang WTP system can be found elsewhere (Mohajit, 2010; 2006).

The mathematical model focuses on the sedimentation and filter unit because these two units represent the performance of the WTP-system as the limiting factors. Development and improvement of the sedimentation and the filter unit will significantly affect the WTP-system performance (Mohajit, 2006; Mohajit and Poedjastanto, 2003).

New configuration of the WTP-system was then defined by modifying the design variable of the sedimentation unit as well as the filter unit. The sedimentation unit was provided with the more efficient and effective plate settler and the filter unit was developed by introducing a new filter media with a coarser gradation but still capable to retain a fine flocs with particle size of 50-80 micron as commonly found in the supernatant of the sedimentation unit.

\section{Result and Discussion}

The Dekeng WTP system of PDAM Kota Bogor was designed for 500 Lps (Liter per second) in capacity with its performance as fair to good performance. The system consists of coagulation unit, flocculation unit, sedimentation unit, filtration unit, and disinfection unit. The system was operated at hydraulic capacity of around 460 Lps and a fair to good performance was reached, and the output of treated water met the drinking water quality standard. 
By modification of the system configuration in the sedimentation unit as well as in the filter unit as reported in detailed in Reference (Mohajit, 2010) it was proven that the Dekeng WTP system could be up-rated from its original capacity of 460 Lps with a fair performance to 1200 Lps in capacity with a good performance. The surface loading of the sedimentation unit was increased much higher from the conventional level of $11.56 \mathrm{mph}$ (meter per hour) to a high rate level of $30.48 \mathrm{mph}$. At this high rate level of loading rate the system is hydraulically still in a laminar and stable condition. No scouring effect on floc particles or sludge washout was observed (Tabel 1).

Table 1. Simulation of Sedimentation Unit for High Rate WTP-system

\begin{tabular}{|c|c|c|c|}
\hline \multicolumn{4}{|c|}{ Mathematical Model for Sedimentation Unit of Water Treatment Plant Systems } \\
\hline \multicolumn{2}{|l|}{ Conventional sedimentation unit } & High rate sedimentation unit & \\
\hline Type (conventional, plate, tube)? & plate & Type of settler (plate or tube) & plate \\
\hline Shape (circular or rectangular)? & rectangular & Shape (circular or rectangular)? & rectangular \\
\hline Total flow rate $(\mathrm{L} / \mathrm{s})$ & 460 & Total up-rated flow rate $(\mathrm{L} / \mathrm{s})$ & 1200 \\
\hline Number of the basin (unit) & 3 & Number of the basin (unit) & 3 \\
\hline Width of the basin $(\mathrm{m})$ & 4.8 & Width of the basin $(\mathrm{m})$ & 4.8 \\
\hline Length of the basin $(\mathrm{m})$ & 10.5 & Length of the basin $(\mathrm{m})$ & 10.5 \\
\hline Depth of the basin (m) & 5.0 & Depth of the basin $(\mathrm{m})$ & 5.0 \\
\hline Length of effluent weir $(\mathrm{m})$ & 88.9 & Minimum length of effluent weir $(\mathrm{m})$ & 89 \\
\hline Surface area $(\mathrm{m} 2)$ & 143 & Efective surface area (m2) & 142 \\
\hline Accelaration due to gravity $(\mathrm{m} / \mathrm{s} 2)$ & 9.81 & Accelaration due to gravity $(\mathrm{m} / \mathrm{s} 2)$ & 9.81 \\
\hline Kinetics viscousity $(\mathrm{m} 2 / \mathrm{s})$ & $8.000 \mathrm{E}-07$ & Kinetics viscousity $(\mathrm{m} 2 / \mathrm{s})$ & $8.000 \mathrm{E}-07$ \\
\hline Temperature $\left({ }^{\circ} \mathrm{C}\right)$ & 30 & Data input : & OK \\
\hline \multicolumn{2}{|c|}{ Demension of plate settler or tube settler } & \multicolumn{2}{|l|}{ Modification of sedimentation unit } \\
\hline Distance between settler $(\mathrm{cm})$ & 9.0 & System configuration $(1,2, \ldots \ldots, 24)$ & sp \\
\hline Thickness of settler $(\mathrm{cm})$ & 0.5 & Thickness of settler $(\mathrm{cm})$ & 0.2 \\
\hline Length of settler $(\mathrm{m})$ & 3 & Degree of up-rating & $261 \%$ \\
\hline Inclined angle of settler $\left({ }^{\circ}\right)$ & 60 & Recommendation & recommended \\
\hline Vertical height of settler (m) & 2.60 & Comment & much better \\
\hline \multicolumn{2}{|c|}{ Performance of sedimentation unit } & \multicolumn{2}{|c|}{ Performance of high rate sedimentation unit } \\
\hline Settleable Settling velocity $(\mathrm{m} / \mathrm{h})$ & 0.79 & Settleable Settling velocity $(\mathrm{m} / \mathrm{h})$ & 0.70 \\
\hline Particulate removal & fair/normal & Particulate removal & good \\
\hline Reynould number & 209 & Reynould number & 183 \\
\hline Freuode number & $3.11 \mathrm{E}-05$ & Freuode number & 6.49E-04 \\
\hline Flow characteristics & laminar flow & Flow characteristics & laminar flow \\
\hline Flow stability & stable flow & Flow stability & stable flow \\
\hline Scouring effect & moderate: none & Scouring effect & moderate: none \\
\hline Current effect & none & Current effect & none \\
\hline Surface loading $(\mathrm{m} / \mathrm{h})$ & 11.56 & Surface loading $(\mathrm{m} / \mathrm{h})$ & 30.48 \\
\hline Detention time (minutes) & 13.5 & Detention time (minutes) & 5.1 \\
\hline Streamliner ratio & $?$ & Streamliner ratio & $\geq 2,5$ \\
\hline
\end{tabular}

Further more by modification of the filter unit with a coarser gradation of the media it can be achieved that the filter unit could be up-rated from its original capacity of 460 Lps with a good performance to 1200 Lps in capacity with a similar performance. 
The filtration rate was increased much higher from a conventional level of $6.4 \mathrm{mph}$ to high rate level of $16.7 \mathrm{mph}$. At this high level of filtration rate the system was still under condition of good performance where the in-plant water losses are less than 5\%. This is acceptable in accordance with the design standard (Table 2). The filtrate of treated water has less than 0.5 NTU of turbidity, and this is much better than the prevailing drinking water standard of 5 NTU.

Table 2. Simulation of Filter Unit for High Rate WTP-system Mathematical Model for Filter Unit of WTP Systems

\begin{tabular}{|c|c|c|c|c|c|c|}
\hline \multicolumn{3}{|c|}{ Filter media analysis } & & Design parameter & 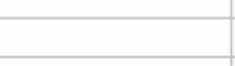 & \\
\hline ASTM & Grain & \multicolumn{2}{|c|}{ Cummulative weight (\%) } & \multirow{2}{*}{$\begin{array}{r}\text { Water temperature }\left({ }^{\circ} \mathrm{C}\right)= \\
\text { Kinematic viscosity, } v(\mathrm{~m} 2 / \mathrm{s})=\end{array}$} & 25 & \\
\hline Sieve & size & Conventional & High rate & & 8.93E-07 & \\
\hline Number & $(\mathrm{mm})$ & media & media & Gravitational acceleration, $\mathrm{g}(\mathrm{m} / \mathrm{s} 2)=$ & 9.81 & \\
\hline 200 & & & & Recommended filter runs $(\mathrm{h})=$ & 24 & \\
\hline 170 & 0.083 & 0 & 0 & Practical factors constant $=$ & 1.96 & \\
\hline 140 & 0.098 & 0 & 0 & Filter run factor $=$ & 0.85 & \\
\hline 120 & 0.116 & 0 & 0 & Required efective size, ES $(\mathrm{mm})=$ & 0.9 & 0.9 \\
\hline 100 & 0.138 & 0 & 0 & Required uniformity coefficient (UC) = & 1.5 & 1.5 \\
\hline 80 & 0.165 & 0 & 0 & Filter media to be used $(1,2)=$ & 1 & silica sand \\
\hline 70 & 0.196 & 0 & 0 & Is medium gradation equal ? (yes, no) & no & Check aX-b! \\
\hline 60 & 0.231 & 1 & 0 & \begin{tabular}{l|l} 
Approximated Vs?
\end{tabular} & OK & OK \\
\hline 50 & 0.275 & 1 & 0 & & Silica sand & Synthetic media \\
\hline 45 & 0.328 & 2 & 0 & Porosity of filter bed, $f=$ & 0.45 & 0.50 \\
\hline 40 & 0.390 & 3 & 0 & Filter media shape factor, $\varphi=$ & 0.82 & 1.00 \\
\hline 35 & 0.463 & 6 & 0 & Specific weight of filter media $=$ & 2.65 & 1.3 \\
\hline 30 & 0.550 & 10 & 0 & & Conventional & High Rate \\
\hline 25 & 0.655 & 16 & 0 & & System & System \\
\hline 20 & 0.780 & 32 & 0 & Code number $(1, \ldots, 5)=$ & 5 & 5 \\
\hline 18 & 0.925 & 60 & 13 & Performance of sedimentation unit $=$ & excellent & excellent \\
\hline 16 & 1.090 & 80 & 31 & \multirow{2}{*}{$\begin{array}{r}\text { Filter capacity }(\mathrm{L} / \mathrm{s})= \\
\text { Number of filters (unit) }=\end{array}$} & 460.0 & 1200.0 \\
\hline 14 & 1.290 & 94 & 53 & & 6 & 6 \\
\hline 12 & 1.550 & 100 & 82 & Surface area of filter unit $(\mathrm{m} 2)=$ & 43.2 & 43.2 \\
\hline 10 & 1.850 & 100 & 100 & Depth of filter bed $(\mathrm{m})=$ & 0.80 & 0.80 \\
\hline 8 & 2.180 & 100 & 100 & Available filter head $(\mathrm{m})=$ & 1.50 & 1.50 \\
\hline 7 & 2.580 & 100 & 100 & Backwashing time (minutes) = & 15 & 15 \\
\hline 6 & 3.075 & 100 & 100 & Backwash rate, $v(\mathrm{~m} / \mathrm{h})=$ & 40 & 40 \\
\hline 5 & 3.675 & 100 & 100 & Filtration rate, $v(\mathrm{~m} / \mathrm{h})=$ & 6.4 & 16.7 \\
\hline 4 & 4.375 & 100 & 100 & Initial head loss; Rose $(\mathrm{m})=$ & 0.58 & 0.51 \\
\hline & & & & Approximated Filter Run $(\mathrm{h})=$ & 66 & 20 \\
\hline & & & & Backwashing head loss $(\mathrm{m})=$ & 0.73 & 0.73 \\
\hline & & & & \begin{tabular}{l|l} 
& Expanded bed $(\mathrm{m})=$
\end{tabular} & 1.07 & 1.07 \\
\hline & & & & \begin{tabular}{l|l} 
& Expansion $(\%)=$
\end{tabular} & $134 \%$ & $134 \%$ \\
\hline & & & & Approximated in-plant losses $( \pm 5 \%)=$ & $2.4 \%$ & $3.0 \%$ \\
\hline & & & Water & production required for backwashing = & $104 \%$ & $40 \%$ \\
\hline & & & & Actual filter head $(\mathrm{m})=$ & 0.92 & 0.99 \\
\hline & & & & Comment: high rate system is & recommended! & \\
\hline & & & & & & \\
\hline & & Estimate & d In-plant W & ater Losses for Filter Backwashing : & & \\
\hline & & & & \begin{tabular}{|l|l} 
& Actual filter run $(\mathrm{h})=$ \\
\end{tabular} & 66 & \\
\hline & & & & Water tariff $(\mathrm{Rp} . / \mathrm{m} 3)=$ & 2500 & 2500 \\
\hline & & & & Unaccounted for water $=$ & $30 \%$ & $30 \%$ \\
\hline & & & & Annual in-plant losses/benefit (Rp.) = & $667,300,000$ & $1,327,800,000$ \\
\hline & & & & \begin{tabular}{l|l} 
& Cross check!: \\
\end{tabular} & reconfirm actual & filter run! \\
\hline
\end{tabular}

Another successful application of HR-WTP system was experienced at Pedindang WTP system where the system was designed for 75 Lps in capacity with its performance as expected fair to good 
performance. The WTP system was a typical pulsator system which consists of coagulation unit, flocculation unit, sedimentation unit, filtration unit, and disinfection unit. The system was actually operated at hydraulic capacity of around 50 Lps and a poor to fair performance was resulted. Table III shows a comparable result in the application of HR-WTP for up-rating and upgrading Dekengand Pedindang WTP system.

It can be seen from the Table III that uprating of Dekeng WTP-system is characterized by a higher surface loading rate of the Sedimentation Unit, i.e., $30.48 \mathrm{mph}$ as compared to the uprating of Pedindang WTP-system (the surface loading rate of the Sedimentation Unit is $26.84 \mathrm{mph}$ ).

On the other hands, the uprating of Pedindang WTP-system is characterized by a higher filtration rate, i.e., $28.7 \mathrm{mph}$ as compared to the uprating of Dekeng WTP-system (the filtration rate is only $16.7 \mathrm{mph})$.

This clearly shows that application of a surface loading as high as $30 \mathrm{mph}$ for Sedimentation Unit and a filtration rate as high as $30 \mathrm{mph}$ are likely feasible and implementable.

Table 3. The performance of HR WTP system application

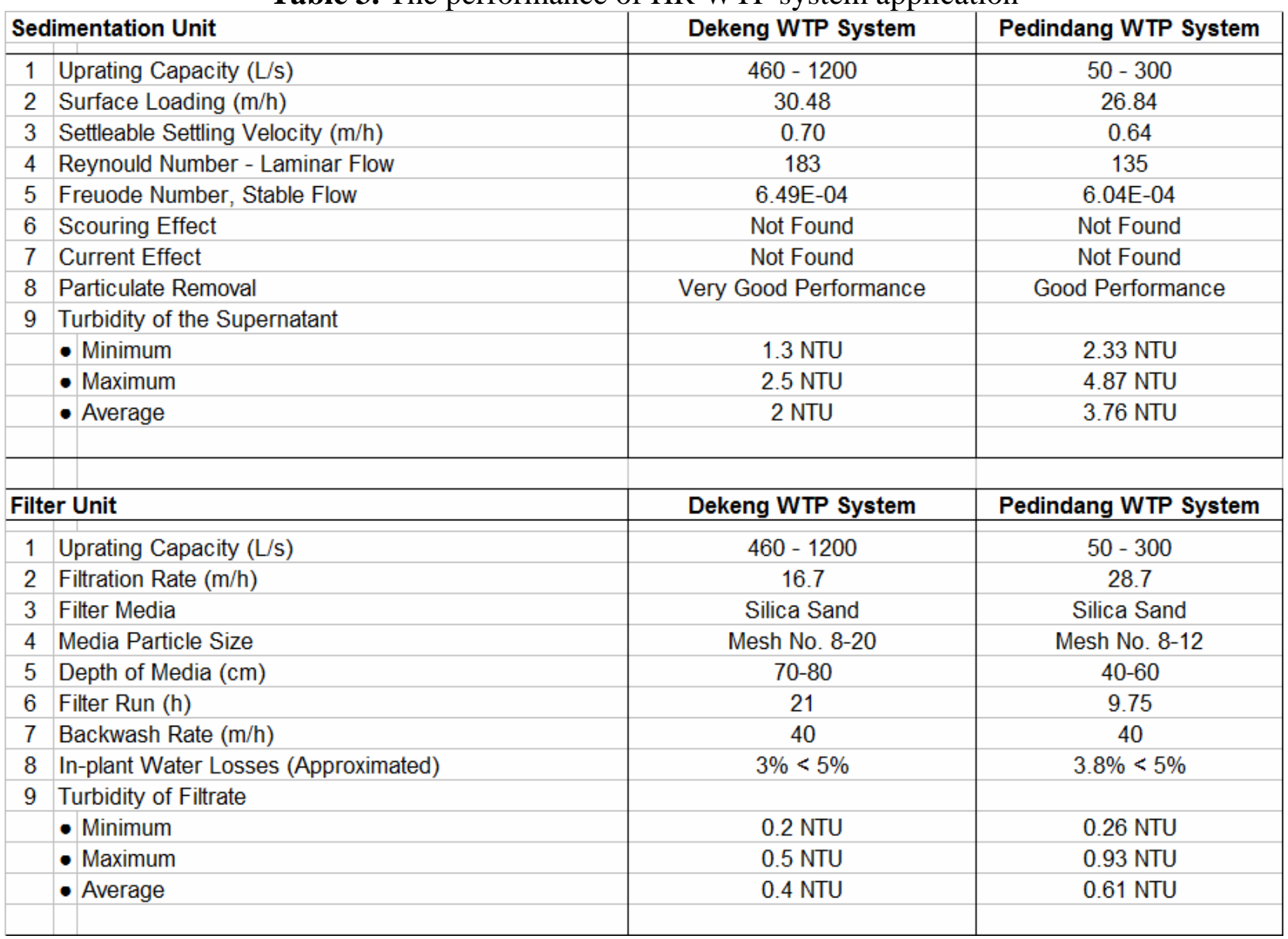




\section{Conclussion}

The HR-WTP system, which is inexpensive, effective and efficient, has been developed to reduce the common operational problems, and also as an alternative for the development of water treatment plant systems capacity in Indonesia.

Implementation of HR-WTP system in up-rating of the Dekeng-WTP system at PDAM Kota Bogor proved successful in increasing the plant capacity from its original of 460 Lps to more than 1200 Lps. Another successful application of HR-WTP system was experienced in the upgrading and uprating of the Pedindang-WTP system at PDAM Kota Pangkalpinang where the plant capacity can be increased from its original of 50 Lps to 300 Lps.

This new approach might be an innovative solution to the challenge of Millennium Development Goals in Water Supply Sector in Indonesia, where an additional capacity of ca 150,000 Lps should be developed within a 15 years period with an estimated budget of US \$1.5 billions.

\section{Acknowledgement}

The author would like to thank to PDAM Kota Bogor and PDAM Kota Pangkapinang for their initiative effort and support in the application and implementation of HR-WTP system. Special correction and suggestion on this paper given by Professor EP Taiganides, $\mathrm{PhD}$ is also acknowledged with many thanks.

\section{References}

Mohajit. (2002). Problems of water treatment in Indonesia due to extreme raw water quality fluctuations, in Seminar Proceedings: Irrigation Water Management in an Intercultural Context, A.H. Malik, P. Oberle and D. Prinz (Editors), Publisher: Institute of Water Resources Management, Hydraulic and Rural Engineering, University of Karlsruhe, Germany.

Mohajit. (2006). "Innovative High Rate and High Performance Water Treatment Plant System, Option for Millennium Development Goals on Water Supply Sector, New Method, Competitive Investment Cost, Effective and Efficient for Operation/Maintenance"; Humboldt International Conference on Biotechnology and Scientific Advances for Socioeconomic Benefits; Penang Malaysia, Organized by University of Sciences Malaysia.

Mohajit. (2010). Successful experience in the application of high rate water treatment plant system, in Seminar Proceedings: The 1st International Conference on Sustainable Technology Development "Sustainable Technology Based on Environmental and Cultural Awareness", Organized by Udayana University of Indonesia in collaboration with Flensburg University of Germany, Denpasar Bali, 7-8 October 2010, pp. C23-C32.

Mohajit and Poedjastanto. (2003). The Development of Water Supply System in Indonesia on the Era of Globalization, in ISTECS Proceedings: International Cooperation in Research and Education for Community Development, ISSN 0855-8692, Technical University - Delft. 